\title{
Rancang Bangun Pembuat Layout PCB Otomatis Berbasis Android
}

\author{
Anggi Hermawan ${ }^{1}$, Dr. Aris Sunawar, ${ }^{2}$, Nur Hanifah Y., ${ }^{3}$. \\ ${ }^{123}$ S1 Pendidikan Teknik Elektro, Fakultas Teknik, Universitas Negeri Jakarta \\ Jalan Rawamangun Muka, Jakarta 13220, Indonesia \\ 1Email: anggi402@gmail.com ; arissunawar@unj.ac.id ; hanifah@unj.ac.id
}

\begin{abstract}
The purpose of this research is to produce an Android-based automatic PCB layout path maker tool. This tool can automatically create a PCB layout path without etching the PCB so that it can provide efficiency in making the PCB layout path.

The research method used in this study used an experimental method with a quantitative approach. This research was conducted at the Jakarta State University Jakarta mechanical workshop laboratory in January 2020, testing carried out namely manual and automatic testing, manual testing including the making of lines and flat shapes using paper media and PCB boards, automatic testing includes making pcb lines automatically using media PCB board.

The conclusion of this research is that the PCB Layout path making tool can automatically work as planned. The tool can make the PCB Layout path according to the design that is sent via Bluetooth communication serial. Automatic PCB layout maker tool has an average error percentage of under 5\%. Testing is done in 2 ways, namely manual and automatic testing, in manual testing the average error is $0.297 \%$ and the automatic error testing is $0.136 \%$.
\end{abstract}

Keywords: Android, Arduino Uno, PCB Path

\begin{abstract}
ABSTRAK
Tujuan penelitian ini adalah menghasilkan alat pembuat jalur layout PCB otomatis berbasis android. Alat ini dapat membuat jalur layout PCB secara otomatis tanpa harus meng-etching PCB sehingga dapat memberikan efisiensi pada pembuatan jalur layout PCB.

Metode penelitian yang digunakan dalam penelitian ini menggunakan metode eksperimen dengan pendekatan kuantitatif. Penelitian ini dilakukan di laboratorium bengkel mekanik Universitas Negeri Jakarta pada bulan Januari 2020, pengujian yang dilakukan yaitu pengujian secara manual dan otomatis, pengujian manual meliputi pembuatan garis dan bangun datar menggunakan media kertas dan papan PCB, pengujian otomatis meliputi pembuatan jalur pcb secara otomatis menggunakan media papan PCB.

Kesimpulan dari penelitian ini adalah alat pembuat jalur Layout PCB secara otomatis dapat bekerja sesuai dengan yang di rencanakan. Alat dapat membuat jalur Layout PCB sesuai dengan desain yang dikirimkan melalui serial komunikasi Bluetooth. Alat pembuat layout PCB otomatis memiliki persentase error rata-rata di bawah 5\%. Pengujian dilakukan dengan 2 cara yaitu pengujian manual dan otomatis, pada pengujian manual rata-rata error didapatkan sebesar 0,297\% dan pengujian otomatis rata-rata error didapatkan sebesar $0.136 \%$.
\end{abstract}

Kata Kunci : Android, Arduino Uno, Jalur PCB

\section{PENDAHULUAN}

${ }^{[1]}$ Penggunaan smartphone saat ini mencapai 2.71 miliar pengguna di seluruh dunia pada tahun 2019 (Statista, 2018). ${ }^{[2]}$ Global Stashot pada 2017 membuat sebuat laporan penelitian penggunaan operating system (OS) di seluruh dunia yang menyatakan $73 \%$ pengguna smartphone di seluruh dunia menggunakan OS Android.

Smartphone dewasa ini tidak hanya digunakan sebagai alat komunikasi namun juga bisa digunakan sebagai pengontrolan suatu peralatan elektronik. Semakin berkembangnya teknologi akan berdampak kepada banyaknya perangkat elektronik yang dapat dikendalikan secara otomatis.
Pada bidang industri elektronik, biasanya pembuatan sebuah rangkaian elektronik dan pemasangan komponen dipasang pada sebuah papan PCB (Printed Circuit Board). Papan sirkuit cetak (PCB) adalah sebuah papan yang digunakan untuk menghubungkan komponenkomponen elektronika dengan lapisan jalur konduktornya tanpa menggunakan kabel penghubung. Cetakan PCB tersebut terdiri atas lubang tempat letak kaki komponen elektronika dan jalur sebagai tempat aliran arus listrik.

Pembuatan jalur PCB dewasa ini masih banyak dilakukan dengan cara manual, yaitu dengan cara menggambar menggunakan drawingpen, transfer papar dan menggunakan stiker yang di tempelkan pada papan PCB yang kemudian masih harus melakukan pelunturan 
tembaga yang tidak terpakai menggunakan cairan feri klorida yang bila mana pada proses pembuatan jalur pada papan PCB tidak sempurna maka pada saat dilakukan pengetching-an akan mendapatkan garis pada layout PCB dengan hasil yang tidak sempurna atau putus jalur.

Dari ketiga cara manual yang dapat dilakukan untuk membuat jalur pada PCB memiliki kelemahan, diantaranya sebagai berikut:

1. Jika dalam pembuatan garis jalur PCB terlalu tipis, tinta tidak menempel merata pada tembaga, dan dalam proses peng-ecthing-an tidak menggunakan air panas dan tidak digoyangkan, maka jalur pada PCB akan hilang dan tidak tersambung dengan sempurna, menyebabkan kegagalan dalam pembuatan PCB.

2. Menggunakan cara manual membuat ukuran PCB menjadi besar, sehingga dari segi cost dan tata letak PCB menjadi kurang efektif.

Selain terdapat kelemahan, pembuatan jalur PCB secara manual juga memiliki kelebihan, dari segi biaya yang dikeluarkan, pembuatan jalur PCB secara manual lebih murah dari otomatis.

${ }_{\text {[3] Dalam penelitian yang berjudul }}$ "Automatic mini CNC machine for PCB drawing and drilling" (Kajal J. Madekar, 2016), memiliki kekurangan yaitu tidak dapat dikendalikan menggunakan android. Begitupun dalam penelitian yang berjudul [4]“"Rancang bangun mesin pengebor PCB mini otomatis berbasis Arduino Uno" (Mukhofidhoh, 2018), memiliki kekurangan yaitu hanya dapat digunakan untuk melubangi PCB dan tidak dapat dikendalikan menggunakan Android.

Dari permasalahan dan penelitian di atas, penulis melihat dalam dunia industri dan otomasi, alat pembuat PCB otomatis dengan kendali android sangat dibutuhkan untuk menunjang segala pekerjaan dan produksi salah satunya dalam pembuatan PCB yang masih banyak dilakukan secara manual di dalam era otomasi dan digital dewasa ini.

Oleh sebab itu untuk menghindari atau mengurangi tingkat kesalahan pembuatan jalur layout PCB secara manual, dibuatlah penelitian (tugas akhir) yaitu rancang bangun pembuat jalur layout PCB otomatis berbasis android. Alat yang memiliki fungsi mengukir/mengikis serta melubangi PCB secara otomatis, dan berbasis aplikasi android.

Rancang bangun alat pembuat jalur layout PCB otomatis diharapkan dapat menjadi alat yang berkompeten dan berguna dalam dunia otomasi industri baik skala nasional maupun internasional.

\section{METODELOGI PENELITIAN}

Penelitian ini dilaksanakan di laboratorium Bengkel Mekanik, Universitas Negeri Jakarta, Jl. Rawamangun Muka, Rawamangun, Kec. Pulo Gadung, Kota Jakarta Timur, Daerah Khusus Ibukota Jakarta 13220. Penelitian ini dilaksanakan dalam rentang waktu Bulan Januari sampai dengan Februari 2020.

Metode penelitian yang digunakan dalam menyelesaikan penelitian ini adalah metode eksperimen laboratorium yang meliputi manipulasi, pengendalian, dan pengamatan.

\section{Prosedur Penelitian}

Pada penelitian ini, peneliti memulai tahap penelitian dari mengidentifikasi masalah yang kemudian dideskripsikan ke dalam latar belakang masalah penelitian. Tahap selanjutnya adalah merumuskan masalah dan menetapkan tujuan serta manfaat penelitian yang akan dicapai. Tahap berikutnya mengkaji teori perancangan, CNC, Arduino dan Driver motor stepper yang dibutuhkan dalam penelitian. Ketika teori perancangan, CNC, Arduino dan Driver motor stepper yang dikaji sudah sesuai, maka selanjutnya adalah tahap perancangan.

Pada tahap perancangan, peneliti merancang sedemikian rupa alat pembuat layout PCB otomatis. Mulai dari alat dan bahan yang digunakan, perancangan diagram blok sistem, perancangan rangkaian (hardware), cara kerja dan perancangan desain mekanik alatnya kemudian diprogram pada Arduino. Perancangan harus dibuat sebaik mungkin agar sejalan dengan tujuan penelitian. Apabila tahap perancangan telah berhasil, maka selanjutnya melakukan perakitan dan pembuatan alat yang kemudian melakukan pengujian pada alat. Ketika pengujian alat berhasil, maka data pengukuran dimasukkan ke dalam tabel untuk dianalisis.

Analisis dilakukan berdasarkan nilai-nilai pengujian yang sudah terdapat dalam tabel pengujian. Hasil pengujian dideskripsikan 
dalam bentuk paragraf. List program-nya dimasukkan. Analisis dilakukan berdasarkan tujuan penelitian yang diharapkan. Kemudian diambil kesimpulan tentang hasil pengujian apakah sesuai dengan tujuan penelitian atau tidak.

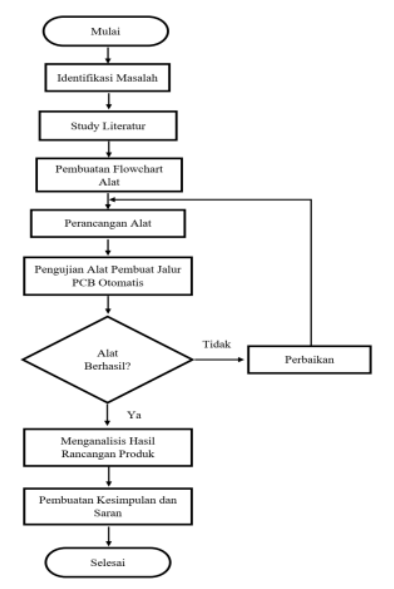

\section{Gambar 1. Prosedur Penelitian}

\section{Gambar Perancangan Alat}

Alat didesain memiliki gerakan yang fleksibel dalam mengikuti instruksi yang diberikan, oleh sebab itu dalam perencanaan konstruksi alat harus dihitung serta dipikirkan secara matang. Alat ini bekerja mengikuti instruksi program yang bergerak secara $\mathrm{X}, \mathrm{Y}$, dan Z. berikut adalah rancangan alat yang akan dibuat sesuai dengan gambar 2 .

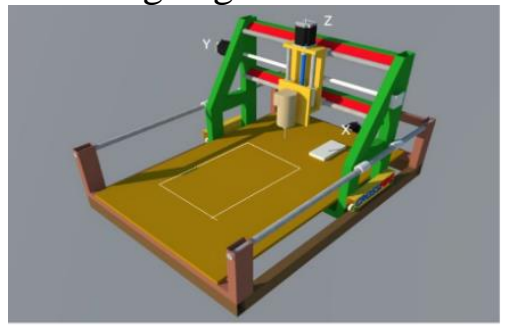

Gambar 2. Rancangan Alat

\section{Diagram Blok Sistem}

Penelitian ini membuat rancang bangun system pembuatan layout PCB secara otomatis berbasis mikrokontroler Arduino Uno. Perancangan sistem terdiri dari dua blok sistem yang terintegrasi menjadi satu sistem. Pembagian blok sistem dibagi menjadi blok user input dan blok hardware. Berikut adalah blok diagram sistem yang dirancang.

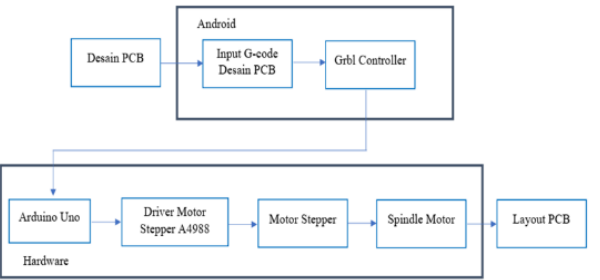

Gambar 3. Diagram Blok Sistem

Masukkan berupa desain PCB yang sudah dibuat dalam bentuk program G-code, lalu program tersebut dimasukkan ke arduino menggunakan software Grbl Controller yang sudah dipasang pada Android. Setelah program G-code dimasukkan maka layar Android akan menampilkan bentuk desain PCB berupa garisgaris yang saling berhubungan, lalu Grbl Controller akan mengirimkan data serial ke dalam Arduino Uno.

Arduino Uno akan memproses data tersebut dan akan mengirimkan sinyal-sinyal digital ke dalam driver motor stepper yang sudah mendapatkan catuan daya dari luar, karena catuan daya dari Arduino tidak mencukupi untuk memutar motor stepper.

Diagram Alir Sistem

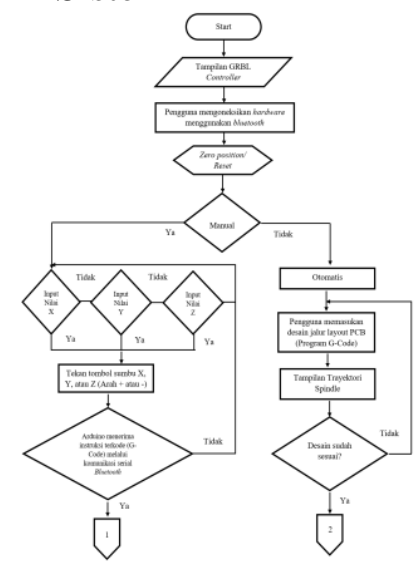

Gambar 4. Diagram Alir Sistem

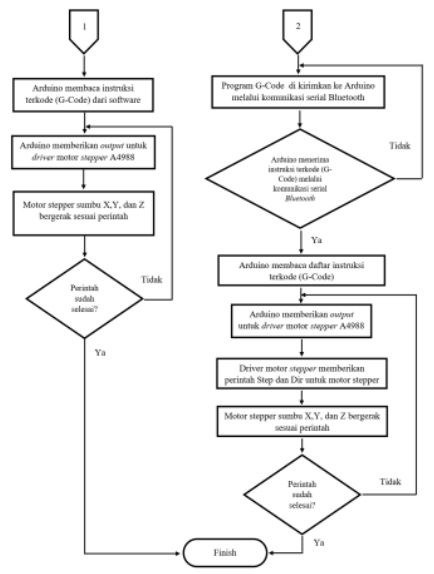

Gambar 5. Diagram Alir Sistem 


\section{Penjelasan Alur Kerja dari Diagram Alir Manual}

1. Pada tampilan awal Grbl Controller lakukan koneksi dengan hardware dengan cara menekan ikon Bluetooth lalu koneksikan dengan Bluetooth hardware.

2. Alat berada pada posisi nol.

3. Lalu jika kita ingin menjalankan alat secara manual, masukan nilai untuk sumbu X,Y, dan Z.

4. jika sudah tekan ikon sumbu pada layar smartphone, maka sumbu yang kita tekan akan berjalan sesuai perintah.

5. Jika motor stepper tidak bergerak, masukan kembali nilai untuk sumbu $\mathrm{X}, \mathrm{Y}$, dan $\mathrm{Z}$ lalu tekan kembali ikon sumbu pada layer smartphone.

6. Arduino menerima instruksi terkode (GCode) melalui serial komunikasi Bluetooth dan akan membaca intruksi tersebut.

7. Arduino akan memberikan Output Step and Dir untuk Driver Motor Stepper A4988.

8. Motor Stepper bergerak sesuai perintah.

\section{Penjelasan Alur Kerja dari Diagram Alir Sistem Otomatis}

1. Pada tampilan awal Grbl Controller lakukan koneksi dengan hardware dengan menekan ikon Bluetooth lalu koneksikan dengan Bluetooth hardware.

2. Alat berada pada posisi nol.

3. pilih "choose file" untuk memilih file desain PCB yang akan dibuat.

4. Pengguna lalu memilih program desain PCB yang sebelumnya sudah dibuat dan mengunggahnya ke Grbl Controller.

5. Setelah pengguna mengunggah program desain PCB pada tampilan Grbl controller akan terlihat trayektori pergerakan Spindle.

6. Program G-Code di kirimkan ke Arduino Melalui serial komunikasi Bluetooth.

7. Arduino menerima Instruksi dan membaca instruksi tersebut, lalu memberikan Output untuk driver motor Stepper A4988.
8. Driver motor Stepper Memberikan perintah Step and Dir untuk menggerakan motor Stepper.

9. Motor Stepper akan bergerak sesuai dengan urutan perintah secara otomatis sampai dengan perintah yang diberikan sudah habis

\section{Teknik Analisis Data}

Teknik analisis data yang digunakan pada penelitian ini dilakukan berdasarkan tahap sebagai berikut:

1. Analisis data dilkakukan dengan membuat table pengujian sumbu/axis pembuat layout PCB otomatis.

2. Dari tabel pengujian sumbu/axis akan didapatkan error rata-rata sumbu/axis serta ketepatan titik axis pembuatan layout PCB otomatis.

3. Analisis dideskripsikan dalam bentuk paragraph. Pada akhir analisis didapatkan kesimpulan hasil penelitian yang

\section{HASIL PENELITIAN DAN PEMBAHASAN Pengujian Manual}

Berdasarkan hasil pengujian secara manual diperoleh rata-rata error adalah sebesar 0,297\%, hasil tersebut diperoleh melalui

Pengujian manual tanpa PCB dan pengujian manual dengan PCB. Berikut di bawah ini ditampilkan data pengujian manual dengan dan tanpa PCB.

Tabel 1. Pengujian Manual Sumbu X

\begin{tabular}{|c|c|c|c|c|}
\hline No. & $\begin{array}{l}\text { Ukuran pada } \\
\text { software }\end{array}$ & $\begin{array}{l}\text { Pengukuran secara } \\
\text { manual }\end{array}$ & $\Delta$ & Error $(\%)$ \\
\hline 1. & $5 \mathrm{~mm}$ & $4.97 \mathrm{~mm}$ & $0.03 \mathrm{~mm}$ & 0.6 \\
\hline 2. & $10.5 \mathrm{~mm}$ & $10.43 \mathrm{~mm}$ & $0.7 \mathrm{~mm}$ & 0.6 \\
\hline 3. & $12.75 \mathrm{~mm}$ & $12.70 \mathrm{~mm}$ & $0.5 \mathrm{~mm}$ & 0.39 \\
\hline 4. & $15 \mathrm{~mm}$ & $14.86 \mathrm{~mm}$ & $0.14 \mathrm{~mm}$ & 0.9 \\
\hline 5. & $25.25 \mathrm{~mm}$ & $25.19 \mathrm{~mm}$ & $0.06 \mathrm{~mm}$ & 0.23 \\
\hline 6. & $30.15 \mathrm{~mm}$ & $30.11 \mathrm{~mm}$ & $0.04 \mathrm{~mm}$ & 0.13 \\
\hline 7. & $40 \mathrm{~mm}$ & $39.93 \mathrm{~mm}$ & $0.07 \mathrm{~mm}$ & 0.17 \\
\hline 8. & $45 \mathrm{~mm}$ & $44.98 \mathrm{~mm}$ & $0.02 \mathrm{~mm}$ & 0.04 \\
\hline 9. & $55.55 \mathrm{~mm}$ & $55.51 \mathrm{~mm}$ & $0.04 \mathrm{~mm}$ & 0.07 \\
\hline 10. & $60 \mathrm{~mm}$ & $59.91 \mathrm{~mm}$ & $0.09 \mathrm{~mm}$ & 0.15 \\
\hline 11. & $62.5 \mathrm{~mm}$ & $62.35 \mathrm{~mm}$ & $0.15 \mathrm{~mm}$ & 0.24 \\
\hline 12. & $67.25 \mathrm{~mm}$ & $67.14 \mathrm{~mm}$ & $0.11 \mathrm{~mm}$ & 0.16 \\
\hline 13. & $68.10 \mathrm{~mm}$ & $67.98 \mathrm{~mm}$ & $0.12 \mathrm{~mm}$ & 0.17 \\
\hline 14. & $70.01 \mathrm{~mm}$ & $69.92 \mathrm{~mm}$ & $0.09 \mathrm{~mm}$ & 0.25 \\
\hline 15. & $72.35 \mathrm{~mm}$ & $72.22 \mathrm{~mm}$ & $0.13 \mathrm{~mm}$ & 0.17 \\
\hline 16. & $75.05 \mathrm{~mm}$ & $75.04 \mathrm{~mm}$ & $0.01 \mathrm{~mm}$ & 0.01 \\
\hline 17. & $78 \mathrm{~mm}$ & $77.83 \mathrm{~mm}$ & $0.17 \mathrm{~mm}$ & 0.21 \\
\hline 18. & $80.15 \mathrm{~mm}$ & $80.13 \mathrm{~mm}$ & $0.02 \mathrm{~mm}$ & 0.02 \\
\hline 19. & $83.35 \mathrm{~mm}$ & $83.26 \mathrm{~mm}$ & $0.09 \mathrm{~mm}$ & 0.11 \\
\hline 20. & $85.25 \mathrm{~mm}$ & $85.18 \mathrm{~mm}$ & $0.07 \mathrm{~mm}$ & 0.08 \\
\hline 21. & $87.75 \mathrm{~mm}$ & $87.67 \mathrm{~mm}$ & $0.08 \mathrm{~mm}$ & 0.09 \\
\hline 22. & $90 \mathrm{~mm}$ & $89.85 \mathrm{~mm}$ & $0.15 \mathrm{~mm}$ & 0.1 \\
\hline 23. & $92.25 \mathrm{~mm}$ & $92.10 \mathrm{~mm}$ & $0.15 \mathrm{~mm}$ & 0.16 \\
\hline 24. & $95.50 \mathrm{~mm}$ & $95.35 \mathrm{~mm}$ & $0.15 \mathrm{~mm}$ & 0.15 \\
\hline \multirow[t]{2}{*}{25.} & $100 \mathrm{~mm}$ & $99.82 \mathrm{~mm}$ & $0.18 \mathrm{~mm}$ & 0.18 \\
\hline & & Rata-rata & & 0.2103 \\
\hline
\end{tabular}

Data di atas adalah pengujian manual untuk sumbu X, diperoleh Error sebesar 0,2103\%. 


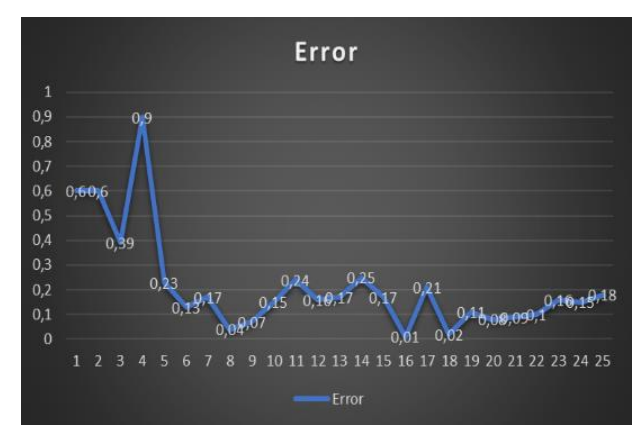

Gambar 6. Persentase Error Sumbu X

Tabel 2. Pengujian Manual Sumbu Y

\begin{tabular}{ccccc}
\hline No. & $\begin{array}{c}\text { Ukuran pada } \\
\text { soffware }\end{array}$ & $\begin{array}{c}\text { Pengukuran secara } \\
\text { manual }\end{array}$ & $\Delta$ & Error (\%) \\
\hline 1. & $5 \mathrm{~mm}$ & $4.97 \mathrm{~mm}$ & $0.03 \mathrm{~mm}$ & 0.6 \\
2. & $10.5 \mathrm{~mm}$ & $10.35 \mathrm{~mm}$ & $0.15 \mathrm{~mm}$ & 1.42 \\
3. & $12.75 \mathrm{~mm}$ & $12.65 \mathrm{~mm}$ & $0.1 \mathrm{~mm}$ & 0.7 \\
4. & $15 \mathrm{~mm}$ & $14.78 \mathrm{~mm}$ & $0.22 \mathrm{~mm}$ & 1.46 \\
5. & $25.25 \mathrm{~mm}$ & $25.20 \mathrm{~mm}$ & $0.05 \mathrm{~mm}$ & 0.19 \\
6. & $30.15 \mathrm{~mm}$ & $30.08 \mathrm{~mm}$ & $0.07 \mathrm{~mm}$ & 0.23 \\
7. & $40 \mathrm{~mm}$ & $39.94 \mathrm{~mm}$ & $0.07 \mathrm{~mm}$ & 0.175 \\
8. & $45 \mathrm{~mm}$ & $44.81 \mathrm{~mm}$ & $0.19 \mathrm{~mm}$ & 0.42 \\
9. & $55.55 \mathrm{~mm}$ & $55.49 \mathrm{~mm}$ & $0.06 \mathrm{~mm}$ & 0.10 \\
10. & $60 \mathrm{~mm}$ & $59.85 \mathrm{~mm}$ & $0.15 \mathrm{~mm}$ & 0.25 \\
11. & $62.5 \mathrm{~mm}$ & $62.35 \mathrm{~mm}$ & $0.15 \mathrm{~mm}$ & 0.24 \\
12. & $67.25 \mathrm{~mm}$ & $67.22 \mathrm{~mm}$ & $0.03 \mathrm{~mm}$ & 0.04 \\
13. & $68.10 \mathrm{~mm}$ & $67.98 \mathrm{~mm}$ & $0.12 \mathrm{~mm}$ & 0.17 \\
14. & $70.01 \mathrm{~mm}$ & $70.00 \mathrm{~mm}$ & $0.01 \mathrm{~mm}$ & 0.014 \\
15. & $72.35 \mathrm{~mm}$ & $72.21 \mathrm{~mm}$ & $0.14 \mathrm{~mm}$ & 0.19 \\
16. & $75.05 \mathrm{~mm}$ & $75.01 \mathrm{~mm}$ & $0.04 \mathrm{~mm}$ & 0.053 \\
17. & $78 \mathrm{~mm}$ & $77.75 \mathrm{~mm}$ & $0.25 \mathrm{~mm}$ & 0.32 \\
18. & $80.15 \mathrm{~mm}$ & $80.14 \mathrm{~mm}$ & $0.01 \mathrm{~mm}$ & 0.012 \\
19. & $83.35 \mathrm{~mm}$ & $83.27 \mathrm{~mm}$ & $0.08 \mathrm{~mm}$ & 0.09 \\
20. & $85.25 \mathrm{~mm}$ & $85.21 \mathrm{~mm}$ & $0.04 \mathrm{~mm}$ & 0.046 \\
\hline & \multicolumn{4}{c}{ Rata-rata } \\
\hline
\end{tabular}

Data di atas merupakan table pengujian sumbu Y secara manual, dan didapatkan persentase Error sebesar $0,354 \%$.

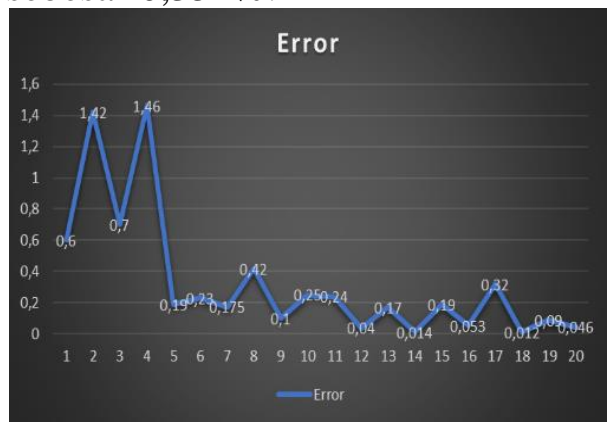

Gambar 7. Persentase Error Sumbu Y

\section{Pengujian Otomatsi}

Pengujian ini merupakan pengujian yang dilakukan dengan memberikan langsung gambar layout PCB kepada alat, dan berikut adalah hasil pengujian secara Otomatis.

Tabel 3. Pengujian Otomatis

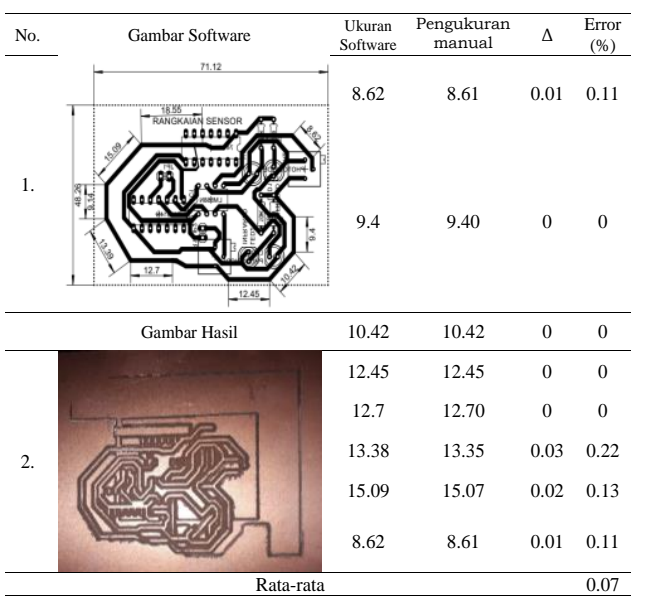

\section{KESIMPULAN DAN SARAN \\ Kesimpulan}

Berdasarkan hasil penelitian yang dilakukan maka dapat disimpulkan bahwa alat pembuat layout PCB otomatis berbasis android sudah dapat bekerja sesuai dengan yang direncanakan. Alat pembuat layout PCB otomatis memiliki persentase error rata-rata di bawah $5 \%$. Pengujian dilakukan dengan 2 cara yaitu pengujian manual dan otomatis, pada pengujian manual rata-rata error didapatkan sebesar $0,297 \%$ dan pengujian otomatis rata-rata error didapatkan sebesar $0.136 \%$.

\section{Saran}

Penelitian tugas akhir ini selanjutnya diharapkan dapat melakukan perbaikan dari apa yang telah penulis lakukan, berikut saran yang dapat diberikan :

1. Pada alat ini digunakan mata bor spindle untuk mencetak papan PCB (Printed Circuit Board) namun menggunakan laser lebih efisien, cepat dan praktis sebagai mesin perkakas daripada menggunakan mata bor.

2. Menggunakan bantalan motor dari bahan yang anti getaran atau vibrasi sehingga objek yang dicetak menjadi semakin presisi dan tepat sesuai yang diiinginkan.

3. Konstruksi mekanik yang lebih presisi akan membuat pengambilan data yang lebih baik. Sehingga diperlukan suatu pengujian mekanik yang lebih baik untuk dapat mengurangi kesalahan pada tiap koordinatnya. 
4. Agar dapat proses pencetakan layout pada PCB lebih cepat dan mendapatkan hasil yang baik sebaiknya menggunakan bor PCB dengan torsi yang lebih besar dan mata bor yang tajam.

\section{DAFTAR PUSTAKA}

[1] Statista. 2018. Number of smartphone users worldwide from 2016 to 2021. https://www.statista.com/statistics/330695/ number-of-smartphone-users-worldwide/ (diakses : 27 November 2019)

[2] Kata, data. 2017. 73\% Perangkat Mobile Global Menggunakan Android. https://databoks.katadata.co.id/datapublish/ 2017/10/09/73-perangkat-mobile-globalmenggunakan-android.(diakses : 27 November 2019)

[3] Kajal, J. M., Kranti, R. N., Pooja, R. P., \& Vikas, S. M. (2016). Automatic mini CNC machine for PCB drawing and drilling. International Journal on Recent and Innovation Trends in Computing and Communication, 3(12), 2041-2042.

[4] Mukhofidhoh, \& Kholis, N. (2018). Rancang Bangun Mesin Pengebor PCB Mini Otomatis Berbasis Arduino UNO. Jurnal Teknik Elektro, 7(1), 9-16 